\title{
LITERATURA E AFRODESCENDÊNCIA NO BRASIL: CONDIÇÕES E POSSIBILIDADES DE EMERGÊNCIA DE UM NOVO CAMPO DE ESTUDOS ${ }^{1}$
}

Rafael Balseiro Zin (PUC-SP)

Resumo: Os primeiros registros da literatura de autoria negra no Brasil datam do início da segunda metade do século XIX. Contudo, os estudos críticos que tratam dessa importante vertente literária ganharam força no país somente nas últimas três ou quatro décadas. Se, por um lado, a potencialidade criativa dos afro-brasileiros ficou esquecida ou mesmo tenha sido silenciada durante esse período, por outro, ela revela a subjetividade e a sensibilidade artística dessa camada de nossa população, apresentando-se como uma forma potente de reinvenção da vida e de construção de novas realidades. Levando em consideração essa perspectiva, o presente artigo se propõe a analisar, dos pontos de vista estrutural e conjuntural, quais foram as condições e as possibilidades que propiciaram a emergência dos estudos contemporâneos que tratam da relação entre literatura e afrodescendência no Brasil.

Palavras-chave: Literatura e afrodescendência; Brasil; Novo campo de estudos.

Abstract: The first records of Brazil's black authorship literature date from the beginning of second half of the nineteenth century. However, the critical studies that deal with this important literary aspect have gained strength in the country only in the last three or four decades. If, on the one hand, the creative potential of Afro-Brazilians was forgotten or even silenced during this period, on the other hand, it reveals the subjectivity and artistic sensitivity of this layer of our population, presenting itself as a powerful form of reinvention life and the construction of new realities. Considering this perspective, this article proposes to analyze, from the

1 As reflexões aqui apresentadas foram inicialmente debatidas em duas oportunidades: a primeira delas, durante as atividades do 50 Encontro Internacional "Pensar o futuro: as histórias que tecemos e as histórias que queremos", promovido e organizado pelo Centro de Pesquisa e Formação do SESC-SP, nos dias 15 e 16 de fevereiro de 2017; a segunda, durante as sessões de comunicação do I Encontro de Pós-Graduandos em Estudos Africanos, organizado pelo Grupo de Trabalho de História da África da Associação Nacional de História - Seção São Paulo (ANPUH-SP) e realizado nas dependências da Pontifícia Universidade Católica de São Paulo, entre os dias 05 e 07 de abril de 2017. 
structural and conjunctural points of view, what were the conditions and possibilities that allowed the emergence of contemporary studies that deal with the relationship between literature and afrodescendence in Brazil.

Keywords: Literature and afrodescendence; Brazil; New field of studies.

\section{INTRODUÇÃO}

Apesar de os primeiros registros da literatura de autoria negra no Brasil datarem do início da segunda metade do século $X I X^{2}$, os estudos críticos que tratam dessa importante vertente literária ganharam força no país somente nas últimas três ou quatro décadas. Se, por um lado, a potencialidade criativa dos afro-brasileiros ficou esquecida ou mesmo tenha sido silenciada durante esse período, por outro, ela revela a subjetividade e a sensibilidade artística dessa camada de nossa população, apresentando-se como uma forma potente de reinvenção da vida e de construção de novas realidades. Do ímpeto autobiográfico à oratória, passando pelo poema, pelo drama e pela ficção, fato é que o negro sempre falou. $E$ o fez, majoritariamente, nas línguas dos colonizadores, que

2 Para efeitos de pesquisa, visando determinar um recorte temporal para análise, parto do princípio de que os pioneiros da chamada literatura afro-brasileira são os autores Luiz Gama (1830-1882), com a publicação de suas Primeiras trovas burlescas de Getulino, em 1859, na cidade de São Paulo; e Maria Firmina dos Reis (1822-1917), com a publicação, naquele mesmo ano, de seu romance inaugural Úrsula, na cidade de São Luís, capital da então província do Maranhão. Embora saibamos da existência de autores negros que desempenharam atividade letrada em período anterior ao sugerido, como o poeta e modinheiro Domingos Caldas Barbosa ou mesmo o advogado e jornalista José da Natividade Saldanha, trilhar sua genealogia continua sendo algo bastante complexo, devido a insuficiência de documentos que possam comprovar determinados aspectos de sua trajetória intelectual, condição comum a muitos escritores e escritoras afrodescendentes no Brasil, sobretudo dos séculos XVIII e XIX. 
aprendeu e, em diversos momentos, rasurou, para emprestar a elas entonações, ritmos, sentidos e vocábulos inteiramente novos. Dessas falas, por vezes isoladas, à constituição de uma literatura, os caminhos trilhados por tais agentes podem ser considerados um tanto tortuosos. E esse processo incluiu a lenta e gradual aquisição do letramento, da escritura e, com o fim da escravização formal, de uma cidadania manca, ainda em fase de consolidação.

Os estudos acerca da presença do negro na literatura brasileira, como nos explica Eduardo de Assis Duarte (2011, p.28), enquanto temática ou autoria, foram, durante um longo período, exclusividade de pesquisadores estrangeiros, o que comprova a hegemonia da chamada branquitude ${ }^{3}$ em nosso país. Em 1943, por exemplo, surge um dos primeiros livros, senão o primeiro, a abordar especificamente a questão: A poesia afro-brasileira, do sociólogo francês Roger Bastide. Tomando como ponto de partida a obra de Domingos Caldas Barbosa e de seu contemporâneo Silva Alvarenga, o pesquisador atravessa o século XIX, passando por autores como Gonçalves Dias, Silva Rabelo, Gonçalves

3 De acordo com a pesquisadora Liv Sovik (2009, P.50): “A branquitude é atributo de quem ocupa um lugar social no alto da pirâmide, é uma prática social e o exercício de uma função que reforça e reproduz instituições, é um lugar de fala para o qual uma certa aparência é condição suficiente. A branquitude mantém uma relação complexa com a cor da pele, formato de nariz e tipo de cabelo. Complexa porque ser mais ou menos branco não depende simplesmente da genética, mas do estatuto social. Brancos brasileiros são brancos nas relações sociais cotidianas: é na prática - é na prática que conta - que são brancos. A branquitude é um ideal estético herdado do passado e faz parte do teatro de fantasias da cultura de entretenimento". 
Crespo e Luiz Gama - todos homens, diga-se de passagem -, detendo-se, de modo mais aprofundado, nos escritos de Cruz e Souza e, já no século XX, de Lino Guedes, além de tecer suas considerações acerca do fenômeno denominado por ele como "puritanismo do preto" (BASTIDE, 1943, p.148). Nas décadas seguintes, as pesquisas de Raymond Sayers (1958 e 1983) e de Gregory Rabassa (1965) trataram da presença do negro na literatura brasileira somente como tema, mas não enquanto voz autoral, apresentando, assim, um plano distinto das ideias iniciais de Bastide. Com o passar dos anos, demais trabalhos de relevo acompanharam as estratégias empreendidas por esses autores estrangeiros, repercutindo, no Brasil, através das obras publicadas por pesquisadores como Teófilo de Queiroz Júnior (1975), David Brookshaw (1983), Oswaldo de Camargo (1987), Zilá Bernd (1987, 1988 e 1992), Benedita Gouveia Damasceno (1988), Domício Proença Filho (1988), Luiza Lobo (1993), entre outros.

Ainda que esses estudos sejam de suma importância para a consolidação de toda uma fortuna crítica dedicada aos escritores e escritoras negros no Brasil, fato é que eles sempre tiveram circulação restrita entre os pesquisadores que investigam o assunto e demais entusiastas. Será somente nas últimas décadas do século XX e a partir dos anos 2000, portanto, 
que o interesse pela literatura afro-brasileira se ampliará, sobretudo por conta da reorganização e do fortalecimento do Movimento Negro no país, já no final da década de 1970, e do surgimento do revisionismo crítico proveniente da chamada "crise dos paradigmas" nas ciências humanas e sociais e de seus reflexos nos estudos literários (DUARTE, 2011, p.29). Levando em consideração essa perspectiva, o presente artigo se propõe a analisar, justamente, dos pontos de vista estrutural e conjuntural, quais foram as condições e as possibilidades que propiciaram a emergência dos estudos contemporâneos que tratam da relação entre literatura e afrodescendência no Brasil.

\section{UM CONCEITO AINDA EM CONSTRUÇÃO}

A chamada literatura "negra", "afro-brasileira" ou "afrodescendente", seja em prosa ou em verso, pela via escrita ou da oralidade, vem passando, nos últimos anos, por um momento frutífero de realizações e de descobertas, ao mesmo tempo em que se situa no fogo cruzado que visa sua consolidação acadêmica, enquanto vertente específica, porém não excludente, da criação literária brasileira. Tratase, assim, de um processo semântico ainda em andamento e que permanece em constante disputa. Mesmo entre os escritores e escritoras que se auto-atribuem como negros, existe certa resistência quanto ao uso de expressões 
adjetivadas como "escritor negro", "literatura negra" ou "literatura afro-brasileira", uma vez que essas denominações, dependendo das circunstâncias, tendem a rotular e a aprisionar sua produção literária. Por outro lado, há quem as considere como algo positivo, já que elas permitem realçar determinados sentidos comumente ocultados pela generalização do termo "literatura". Seja como for, tais definições dizem respeito aos valores e imbricamentos de um segmento social que luta, até hoje, contra o preconceito e a exclusão impostos pelo conjunto da sociedade brasileira (FONSECA, 2006, p.13).

Dentre os intelectuais que se debruçaram sobre o assunto, Luiza Lobo (1993, p.222) afirma que um dos aspectos primordiais, que caracteriza a literatura afro-brasileira, é o fato dela ter surgido no momento em que o negro passa de objeto a sujeito da criação, deixando de ser tema para autores brancos e passando a registrar a sua própria visão de mundo. De modo mais abrangente, Eduardo de Assis Duarte (2014, p.41) esclarece que essa vertente de nossa literatura é um conceito em construção, processo e devir. Além de segmento e linhagem, é componente de amplo encadeamento discursivo. Ao mesmo tempo, dentro e fora da literatura brasileira, constituindo-se a partir de textos que apresentam temas, autores, linguagens, mas, 
principalmente, um ponto de vista culturalmente identificado à afrodescendência, com começo, meio e fim. Outros teóricos, no entanto, defendem a manutenção da expressão "literatura negra", mesmo após a popularização do termo "literatura afrobrasileira". É o caso do escritor Cuti, pseudônimo de Luiz Silva, que, contrapondo-se às concepções anteriores, sugere que:

Denominar de afro a produção literária negro-brasileira (dos que se assumem como negros em seus textos) é projetá-la à origem continental de seus autores, deixando-a à margem da literatura brasileira, atribuindo-lhe, principalmente, uma desqualificação com base no viés da hierarquização das culturas, noção bastante disseminada na concepção de Brasil por seus intelectuais. "Afro-brasileiro" e "afrodescendente" são expressões que induzem a discreto retorno à África, afastamento silencioso no âmbito da literatura brasileira para se fazer de sua vertente negra um mero apêndice da literatura africana. Em outras palavras, é como se só à produção de autores brancos coubesse compor a literatura do Brasil. [...] A literatura negro-brasileira nasce na e da população negra que se formou fora da África, e da sua experiência no Brasil. A singularidade é negra e, ao mesmo tempo, brasileira, pois a palavra "negro" aponta para um processo de luta participativa nos destinos da nação e não se presta ao reducionismo contribucionista a uma pretensa brancura que a englobaria 
como um todo a receber, daqui e dali, elementos negros e indígenas para se fortalecer. Por se tratar de participação na vida nacional, o realce a essa vertente literária deve estar referenciado à sua gênese social ativa. $O$ que há de manifestação reivindicatória apoia-se na palavra "negro". (2010, p.35-36, p.44-45)

Ao considerarmos essas conceituações, logo, o que se evidencia é que a denominação "literatura negra", ao se integrar às lutas pela conscientização da população negra, toma como seu objetivo central a atribuição de novos sentidos ao processo de formação da identidade de grupos étnicos que foram apartados do modelo social "hegemônico" proposto pelo Estado brasileiro, ou seja, o da branquitude, fazendo com que as imagens negativas que o termo "negro" assumiu ao longo da história pudessem ser revertidas. Já a expressão "literatura afro-brasileira", ao se propor mais abrangente e menos direcionada politicamente, busca assumir as ligações entre o ato criativo próprio do fazer literário e a relação dessa criação com o continente africano, seja aquela que nos legou as populações escravizadas trazidas para as Américas, seja a África venerada como berço da civilização. Não obstante, a chamada "literatura afrodescendente", expressão genérica e menos usual, parece se orientar por um movimento de mão dupla: insiste na constituição de uma visão vinculada às matrizes 
culturais africanas e, concomitantemente, procura traduzir as mutações inevitáveis que essas heranças sofreram durante o processo diaspórico (FONSECA, 2006, p.23-24).

Sem pretender esgotar o debate, em linhas gerais, será a partir da formação de um cânone literário homogêneo, constituído por uma grande maioria de escritores brancos do sexo masculino, que a literatura de autoria negra no Brasil se distinguirá, já que ela apresentará novas possibilidades estéticas para a formulação dos textos literários, revelando, assim, uma polifonia de vozes ainda distanciadas de um público mais amplo, especializado ou não. A literatura negra ou afro-brasileira, finalmente, uma vertente da literatura brasileira, será aquela que apresenta as autorias negras expondo suas subjetividades, a partir da vivência de ser negro no Brasil, reelaborando histórias, atualizando experiências e discursos, nos quais a violência do cativeiro e do pósabolição, por muito tempo, as impediram de vir à tona.

\section{A EMERGÊNCIA DE UM NOVO CAMPO DE ESTUDOS ${ }^{4}$}

Um primeiro movimento para compreendermos como se deu a emergência dos estudos contemporâneos que

\footnotetext{
4 A noção de campo ou campo de poder que norteia essa parte de minhas reflexões é emprestada da teoria social proposta por Pierre Bourdieu (1989, p.315), a saber: "Entendo por campo de poder as relações de força entre as posições sociais que garantem a seus ocupantes um quantum suficiente de força social - ou de capital - de modo a que estes tenham a possibilidade de entrar nas lutas pelo monopólio do poder".
} 
tratam da relação entre literatura e afrodescendência no Brasil é observarmos, ainda que rapidamente, o papel que os estudos culturais ingleses, ao longo da década de 1960, exerceram enquanto facilitadores do processo. Isso porque, como explica a pesquisadora Maria Elisa Cevasco (2003), numa perspectiva explicitamente engajada dessa disciplina em ascensão, a noção de cultura passou a ser entendida não mais sob a égide das grandes estruturas estruturadas e estruturantes, mas como a organização dos significados e dos valores de um determinado grupo social, ao mesmo tempo em que se constituía como um campo de disputas em que estes pudessem ser modificados na direção de um mundo mais democrático, plural e inclusivo. Aproximando suas reflexões para o âmbito de uma teoria da produção e da reprodução social, os estudos culturais trouxeram para o debate a ideia de que as sociedades deveriam ser entendidas enquanto um conjunto hierárquico e antagonista de relações sociais, comumente balizadas por opressões de classe, de gênero, de raça e demais marcadores de diferença.

Além desses avanços, em resposta à proliferação de manifestações culturais que se tornavam cada vez mais abundantes, essa nova disciplina fez com que o campo já consolidado dos estudos literários se expandisse, 
abrangendo, assim, os mais variados tipos de expressão simbólica. Partindo do princípio de que é preciso pensar a cultura na história, essa nova corrente de pensamento também se fez sentir no Brasil, trazendo à tona, entre outros aspectos, a possibilidade de se examinar as aproximações e os distanciamentos entre a chamada alta literatura e a produção literária não-canônica. Nesse contexto, consequentemente, a literatura afro-brasileira, ao expor as mazelas e a natureza profundamente desigual de nossa sociedade, encontrou uma brecha para denunciar o preço de se viver em um país onde o fazer literário continua sendo reserva de classe e em que boa parte da população é excluída tanto de sua produção quanto de sua fruição.

Um segundo marco importante se deu já no final da década de 1970 no Brasil, mais precisamente em 7 de julho de 1978, quando as escadarias do Teatro Municipal de São Paulo se tornaram palco do ato público que convocava homens e mulheres negros a reagirem à violência policial a qual eram submetidos cotidianamente, o que deu origem ao Movimento Negro Unificado Contra a Discriminação Racial (MNDCR), cuja denominação logo passou a ser Movimento Negro Unificado (MNU), apenas. O MNU nasceu quando representantes de várias entidades sociais se reuniram em 
resposta à discriminação sofrida por quatro garotos negros do time infantil de voleibol do Clube de Regatas Tietê, e à prisão, tortura e morte de Robson Silveira da Luz, jovem de vinte e sete anos acusado de roubar frutas em uma feira. Internacionalmente, o enfoque era a independência das então colônias africanas e a intenção do governo brasileiro de manter relações comerciais com esses países (ALVES, 2012, p.221-222). Após o ato no Teatro Municipal, que reuniu cerca de duas mil pessoas, o MNU lutou para fazer com que a população negra saísse das salas de debates e das atividades lúdicas e desportivas, para desenvolver ações mais efetivas de enfrentamento aos constantes atos de racismo sofridos por ela, elaborando panfletos e jornais, realizando manifestações públicas e criando núcleos organizados em associações recreativas, de bairro, de trabalhadores, além de universidades públicas e privadas (PEREIRA, 2008).

No bojo de toda movimentação política que o MNU gerou, naquele mesmo ano, em 1978, ocorre na cidade de Araraquara, interior de São Paulo, o lançamento do primeiro volume da série Cadernos Negros, publicação de cunho independente e que reuniu os trabalhos de oito poetas afrobrasileiros ${ }^{5}$ que, sozinhos, dividiram os custos da edição. Ao

5 A saber: Henrique Cunha, Angela Lopes Galvão, Eduardo de Oliveira, Hugo Ferreira, Célia Pereira, Jamu Minka, Oswaldo de Camargo, Luiz Silva (Cuti). 
rememorar essa história, Cuti (2010, p.126) nos conta que o Centro de Cultura e Arte Negra, naquela época situado no bairro do Bixiga, na capital paulista, foi o ponto de encontro entre os autores que iniciaram a série. Com a colaboração de Isidoro Telles, um dos diretores da instituição, o próprio Cuti encaminhou os originais para a gráfica, responsabilizando-se pela coleta da contribuição financeira a ser feita por cada um. Em novembro, a brochura de bolso, contendo cinquenta e duas páginas, foi colocada em circulação com uma tiragem de mil exemplares. No ano seguinte, em 1979, a quantidade de autores passou de oito para catorze, sendo alguns "de manifestações político-culturais de décadas passadas, como José Correia Leite e Aristides Barbosa" (ALVES, 2012, p.228). No terceiro número, publicado em 1980, vinte e um nomes compuseram a coletânea, que passou, inclusive, a incorporar escritores negros dos demais estados brasileiros. Desde então, ininterruptamente, já foram lançados, ao todo, trinta e nove edições, sendo uma por ano, que alternam a publicação de poemas e contos de estilos diversos ${ }^{6}$. Vale dizer que não há quaisquer registros de outras antologias veiculadas com essa regularidade no Brasil e que contenham,

\footnotetext{
6 Miriam Alves (2012, p.230) afirma que: “Vários estudos sobre literatura negra começaram a pulular após a continuidade dos Cadernos Negros e toda a efervescência criada a partir e ao redor dessas várias realizações". Nesse ano de 2017, vale lembrar, está previsto o lançamento da edição de número 40.
} 
exclusivamente, textos de escritores e escritoras afrobrasileiros, o que mostra a importância dessa iniciativa para dar visibilidade e para a consolidação dessa importante vertente literária no país ${ }^{7}$.

Em 1980, também, esse mesmo grupo de autores que deu vida às primeiras edições dos Cadernos, com o intuito de ampliar o alcance de suas intenções iniciais, decidiu fundar o coletivo paulistano Quilombhoje Literatura, cuja finalidade, desde o início, é promover discussões e aprofundar a experiência afro na literatura brasileira. Dentre seus idealizadores, destacam-se os nomes dos escritores Cuti, Oswaldo de Camargo, Abelardo Rodrigues, Paulo Colina e Mario Jorge Lescano. A dinâmica dos primeiros encontros, por sua vez, funcionava como uma espécie de sarau personalizado:

Além das conversas em bares do centro de São Paulo, o grupo passou a realizar

7 Os anos finais da década de 1970, ainda, foram marcados por inúmeros encontros entre grupos de escritores negros de diversos lugares do Brasil. Como nos explica Cuti (2010, p.126127): "Nesses encontros a poesia sempre se fez presente, quer em representações dramáticas, quer em simples declamações. Os autores preferidos, em São Paulo: Solano Trindade e Carlos Assumpção. Esses encontros redundaram em contatos de autores novos e alguns da geração anterior. Em 1976, o Centro de Estudos Culturais Afro-Brasileiro Zumbi (Santos-SP) publicou a 'Coletânea de Poesia Negra' (mimeografada), onde se faziam presentes textos de autores negros da África e da América (incluindo brasileiros já publicados em livros). Por esse tempo, o jornal Árvore das Palavras corria de mão em mão. Era xerografado e apócrifo. Veiculava notícias das revoluções africanas nas então colônias portuguesas e trazia uma mensagem de consciência política do negro brasileiro. Surgia sem que se soubesse onde. No ano de 1977 é lançado no Rio de Janeiro o jornal Sinba - órgão de divulgação da Sociedade de Intercâmbio Brasil-África, que reforçou mais os contatos, estimulando as organizações dos grupos. Neste mesmo ano (1977), em São Paulo, foi impressa em mimeógrafo a coletânea Negrice I - contendo textos de poetas negros contemporâneos, uns novatos, outros não". 
as rodas de poema, uma maneira própria de se dizer poesia, semelhante à roda de samba, que incluía instrumentos de percussão (em geral atabaques e chocalhos) e pequenos pontos musicais para serem cantados pelos participantes entre uma e outra declamação ou leitura em voz alta no centro da roda. Essas atividades recebiam títulos referentes a nomes de pessoas ilustres da cultura negro-brasileira ou estrangeira, como Luiz Gama, Pixinguinha, Agostinho Neto e outros. (CUTI, 2010, p.125)

O Quilombhoje se mantém em atividade até hoje e continua estimulando o hábito da escrita e da leitura de autores afro-brasileiros, bem como desenvolve estudos, pesquisas e diagnósticos sobre os demais aspectos da cultura negra no país ${ }^{8}$. Atualmente, o coletivo é coordenado pela jornalista e escritora Esmeralda Ribeiro e pelo escritor e pesquisador Márcio Barbosa.

Mais recentemente, podendo ser considerada como o elemento aglutinador de toda a conjuntura anterior, ganha destaque a antologia Literatura e afrodescendência no Brasil,

\footnotetext{
8 Além do Quilombhoje, ainda de acordo com Cuti (2010, p.130-131), mais dois coletivos negros com atuação fora de São Paulo merecem destaque: "o Grupo Negrícia - Poesia e Arte de Crioulo, da cidade do Rio de Janeiro, contando, dentre outros, com Éle Semog, Hélio de Assis, Deley de Acari e Hermógenes Almeida. Na cidade de Salvador, foi criado o GENS - Grupo de Escritores Negros de Salvador, tendo à frente Jônatas Conceição da Silva. A história desses grupos, ao ser escrita, comporá o mosaico que se formou da vida literária negra no Brasil, que, além de animar a criação de obras, promoveu durante certo período importante produção epistolar, em um tempo em que não havia e-mails e a carta era o privilegiado veículo de comunicação escrita interpessoal".
} 
publicada, em 2011, pela Editora da UFMG, e organizada pelos professores Eduardo de Assis Duarte e Maria Nazareth Soares Fonseca. Composta de quatro volumes, a coleção é fruto de um projeto ousado de pesquisa, realizado em todas as regiões do país, com o objetivo de mapear a produção literária de autores afro-brasileiros, da Colônia à República. O levantamento, que durou cerca de dez anos, foi desenvolvido por sessenta e um pesquisadores, vinculados a vinte e uma instituições de ensino superior brasileiras e mais seis estrangeiras. O resultado de todo esse esforço revelou a face afro da literatura nacional, trazendo à tona cerca de duzentos e cinquenta nomes, mas tendo sido divulgados um total exato de cem escritores e escritoras oriundos de tempos e espaços diversos, sempre apresentados a partir de ensaios críticos, contendo dados biobibliográficos, estudo da obra, relação de publicações, além de fontes e demais referências para consulta. Trata-se, portanto, de um acontecimento inédito na história da literatura brasileira e que trouxe ao alcance do leitor contemporâneo essas vozes esquecidas e que, por um longo período, estiveram fadadas ao silêncio.

O primeiro volume da coleção, intitulado Precursores, é dedicado aos escritores nascidos antes da década de 1930 e cobre um amplo painel, que se inicia no século XVIII, com 
Domingos Caldas Barbosa, passando por nomes como os de Luiz Gama e de Maria Firmina dos Reis, com suas obras inaugurais publicadas em meados do século XIX, chegando a Machado de Assis, José do Patrocínio, Cruz e Souza e Lima Barreto. Abarca, também, autores com atuação no século XX, tais como Nascimento Moraes, Lino Guedes, Solano Trindade, Abdias do Nascimento, Carolina Maria de Jesus, Mestre Didi, Eduardo de Oliveira, Carlos Assumpção e outros. O segundo volume, Consolidação, contempla os escritores nascidos nas décadas de 1930 e 1940, reunindo um conjunto de trinta personalidades negras de diferentes tendências, com publicações realizadas a partir de meados do século XX. Apresenta nomes como os de Joel Rufino dos Santos, Muniz Sodré, Conceição Evaristo, Nei Lopes e Martinho da Vila, além de autores que tiveram menor circulação nacional, como Oswaldo de Camargo, Geni Guimarães, Francisco Maciel, Maria Helena Vargas e Eustáquio José Rodrigues. De acordo com Eduardo de Assis Duarte (2011, p.37), em grande medida, são agentes cuja produção se distingue no panorama da literatura brasileira da segunda metade do século $X X$, por apresentarem temas, linguagens e, especialmente, pontos de vista marcados pelo pertencimento étnico e pelo propósito de construírem em seus textos perspectivas afroidentificadas. 
O terceiro volume da coleção, por conseguinte, intitulado Contemporaneidade, reúne autores negros de gerações mais recentes, com publicações realizadas a partir das últimas décadas do século XX e início do XXI. Há uma forte presença de escritores revelados nos Cadernos Negros, como Cuti, Miriam Alves, Esmeralda Ribeiro, Márcio Barbosa, Abílio Ferreira, Lia Vieira, Sônia Fátima da Conceição, Fausto Antônio, Ramatis Jacino e Abelardo Rodrigues, além de nomes mais conhecidos em suas localidades, como Éle Semog, José Carlos Limeira e Jônatas Conceição. Não menos importante, figuram nesse número os nomes dos poetas Edimilson de Almeida Pereira, Salgado Maranhão e Ronald Augusto, bem como os ficcionistas Adilson Vilaça, Paulo Lins, Luís Carlos de Santana e Ana Maria Gonçalves. O quarto e o último volume, por fim, intitulado História, teoria e polêmica, é composto por depoimentos e ensaios de escritores, críticos e historiadores da nossa literatura, tendo como objetivo central fornecer aos pesquisadores e pesquisadoras interessados no assunto não somente dados historiográficos, mas subsídios teóricos e conceituais acerca da produção literária de autoria negra no país.

Tal coletânea, portanto, ao disponibilizar de uma única vez esse imenso material para consulta, acabou contribuindo 
para o surgimento de novos trabalhos sobre a vida e a obra de escritores negros brasileiros, assumindo vital importância para compreendermos como se deu, já nesse início de século, a consolidação dos estudos que tratam da relação entre literatura e afrodescendência no país. Nas palavras de seu organizador, ainda, ela:

Cumpre seu objetivo de antologia crítica ao abrir espaço para que profissionais dos estudos literários possam apresentar a trajetória dessa centena de autores, analisar o perfil de seus escritos e as opções estéticas adotadas por cada um. Traz ainda a memória, a teoria e a discussão da literatura nascida dessas vozes d'África presentes no Brasil. Vozes grafadas, enredadas em seres de papel e figuras de ficção, a nos lembrar a todo instante o mundo em que vivemos, hoje, e em que viveram, ontem, nossos antepassados. (DUARTE, 2011, p.39)

Como resultado de todo esse processo, tendo se tornado mais abundante a partir dos anos 2000, um número considerável de dissertações e teses acadêmicas que tratam da produção literária afro-brasileira vem sendo desenvolvido em universidades públicas e privadas de todo o país ${ }^{9}$, bem

9 Um exemplo bastante interessante a ser observado é a proliferação de pesquisas acadêmicas que tratam de determinados aspectos ligados à vida e obra da escritora maranhense Maria Firmina dos Reis e que, muito recentemente, têm sido desenvolvidas em programas de pósgraduação nas áreas de Letras (MENDES, 2006; OLIVEIRA, 2007; NASCIMENTO, 2009; ABREU, 2013; CARVALHO, 2013; RIO, 2015. PINHEIRO, 2016), de História (SILVA, 2013; CORREIA, 2013; MENDES, 2013), de Ciências Sociais (TELLES, 1987; ZIN, 2016), de Educação (SANTOS, 2016) e nas áreas interdisciplinares de Cultura e Sociedade (SANTOS, 2015) e de Estudos Brasileiros (DIOGO, 
como, atualmente, podemos encontrar uma quantidade significativa de artigos científicos e demais ensaios que são veiculados em livros ou periódicos especializados no assunto. O que se constata, dessa maneira, é que foram necessárias pouco mais de quatro décadas após a publicação do livro inaugural de Roger Bastide (1943) para que a literatura de autoria negra no Brasil ganhasse uma recepção crítica minimamente consistente, embora aquém do necessário ${ }^{10}$, frente à diversidade estética que marca essa vertente específica das letras nacionais (DUARTE, 2011, p.30).

\section{DEMAIS ASPECTOS POLÍTICO-INSTITUCIONAIS QUE CONTRIBUÍRAM PARA A FORMAÇÃO DO CAMPO}

Ao analisar os principais dilemas que envolvem a luta contra o preconceito e a discriminação racial no país, Dennis de Oliveira (2016, p.31) afirma que o movimento negro brasileiro cumpriu um papel importantíssimo quando, em 1995, durante a marcha à Brasília em celebração aos trezentos anos de Zumbi dos Palmares, forçou o governo federal, pela primeira vez na história, a reconhecer oficialmente a

2016), tanto em nível de mestrado quanto de doutorado. Ainda que boa parte desses estudos se concentre em analisar especificamente o romance Úrsula, desconsiderando, por vezes, os demais textos da autora, é inegável sua relevância para a construção e para a consolidação de toda uma fortuna crítica dedicada a ela.

10 Com relação a esse ponto, é preciso lembrar que o mercado editorial brasileiro ainda se mantém bastante reticente à publicação de obras literárias feitas por autores negros no país, que, sem poder contar com essa possibilidade, acabam veiculando seus textos com recursos próprios ou através de pequenas editoras, às vezes independentes. 
existência do racismo em solo brasileiro. Naquele momento, o então presidente da República, Fernando Henrique Cardoso, recebeu uma comissão executiva da marcha e nomeou um Grupo de Trabalho Interministerial para formular políticas públicas que focassem na promoção da igualdade racial no Brasil. Já no ano de 2001, de acordo com o pesquisador, houve uma ação por parte de setores do governo, como o Ministério das Relações Exteriores e o Ministério da Cultura, com o apoio da Fundação Cultural Palmares, junto ao movimento negro organizado, para a preparação do país para participar da III Conferência Mundial de Combate ao Racismo, convocada pela Organização das Nações Unidas e realizada, naquele mesmo ano, na cidade sul-africana de Durban. A partir de então, uma série de reuniões, pré-conferências temáticas e seminários aconteceram, resultando em um documento oficial por parte do Estado brasileiro comprometendo-se com a implementação de políticas de ação afirmativa, a fim de combater esse triste cenário no país.

Nesse período, também, demais avanços políticoinstitucionais foram colocados em prática pelo governo federal, sendo uns mais efetivos que outros e tendo maior concentração nas gestões Lula e Dilma Rousseff, o que forneceu um caldo de conquistas sociais jamais experienciadas pela população negra brasileira, dentre as quais, podemos destacar: i) a tipificação 
do crime de racismo inserida na carta constitucional de 1988, como inafiançável e imprescritível ${ }^{11}$; ii) a obrigatoriedade do ensino de história da África e de cultura africana e afrobrasileira no ensino básico de todo o país ${ }^{12}$; iii) a criação do Estatuto da Igualdade Racial, que garante à população negra brasileira a efetivação da igualdade de oportunidades e a defesa dos direitos étnicos individuais, coletivos e difusos, além do combate à discriminação e às demais formas de intolerância ${ }^{13}$; iv) a implantação de cotas raciais e sociais para o ingresso nas universidades públicas federais ${ }^{14}$ e de cotas raciais para o provimento de cargos em concursos públicos da União a todos aqueles que se autodeclararem negros ${ }^{15}$; além da v) criação de organismos específicos para tratar das políticas de enfrentamento ao preconceito e à discriminação, como a Secretaria Nacional de Políticas de Promoção da Igualdade Racial, atualmente vinculada ao Ministério dos Direitos Humanos.

Como resultante desses dispositivos legais, o combate ao racismo no Brasil transcendeu a simples denúncia para

11 Regulamentado por meio da Lei no 7.716, de 5 de janeiro de 1989.

12 Garantida pela Lei no 10.639, de 9 de janeiro de 2003, e complementada pela Lei no 11.645, de 10 março de 2008, que altera a Lei de Diretrizes e Bases da Educação Nacional, incluindo, no currículo oficial da rede de ensino, a obrigatoriedade da temática História e Cultura AfroBrasileira e Indígena.

13 Instituído pela Lei no 12.288, de 20 de julho de 2010.

14 Colocada em prática por meio da Lei no 12.771, de 28 de dezembro de 2010.

15 Estabelecida pela Lei no 12.990, de 9 de junho de 2014. 
o reconhecimento de sua existência e, finalmente, para ser incluído na dimensão institucional da formulação das políticas públicas (OLIVEIRA, 2016, p.32). No que diz respeito à aplicação da Lei no 10.639, especificamente, considerada a mais importante para a consolidação dos estudos contemporâneos que tratam da relação entre literatura e afrodescendência no país ${ }^{16}$, diversas pesquisas têm demonstrado as fragilidades e as dificuldades de seu aproveitamento nas escolas públicas e particulares, de norte a sul. Mesmo assim, ela tem sido um instrumento fundamental para garantir a presença desses conteúdos contra-hegemônicos em salas de aula, revelando os perigos que a narrativa única, influenciada por componentes exclusivamente eurocentrados, trazem para a constituição da diversidade que compõe o conjunto da sociedade brasileira. De modo geral, portanto, podemos afirmar que são esses os demais aspectos político-institucionais que contribuíram, ainda que indiretamente, para a configuração e para o estabelecimento desse novo campo de estudos no país.

\section{CONSIDERAÇÕES FINAIS}

Ao avaliar o papel que os críticos e demais estudiosos da literatura afro-brasileira vêm desempenhando nos últimos

16 Adianto que essa discussão será aprofundada em um novo artigo, que tratará apenas dessa questão. 
anos, sobretudo após a publicação das primeiras edições dos Cadernos Negros, Miriam Alves (2012, p.235), em tom de desabafo, afirma o seguinte:

A produção literária de autores e autoras negros vive verdadeiros sacos de varas. Primeiro é acusada de essencialismo, depois é punida com o anonimato. Trata-se de um anonimato complexo, que retira a legitimidade do negro como escritor. A esse escritor é reservado um lugar de objeto de estudos no discurso de pesquisadores, ou seja, alguém que só tem existência através do agenciamento do outro. Em última análise, reduz-se a capacidade de um trabalho de criação literária. Nesse saco de sutilezas, além de uma manifestação de perplexidade, pode-se traduzir: como é que o negro se atreve a ser escritor, agenciando as interioridades de um "devir negro"? $\mathrm{Na}$ verdade, existe a prática de defender o status quo da literatura e a visão de que é um lugar reservado a determinados assuntos, específicos das suas formas de abordagem.

Autodenominar-se escritor de literatura negra é embrenhar-se nessa selva de significados, relações e inter-relações, procurando uma outra forma de expressão literária. A existência de uma literatura específica se dá através de um conjunto de significados e intenções, símbolos, estéticas e a tradução em arte dessa visão do mundo. Assim, o termo "negro" não designa, aqui, a cor 
epidérmica de alguém. Antes de tudo, era um termo pejorativo, utilizado na escravidão para diminuir e inferiorizar. [...] Ao inverter-se a intenção negativa do termo, a literatura negra obrigase também a inverter o olhar sobre o brasileiro negro, tirando-lhe a máscara da invisibilidade e dando existência ao que se considera massa amorfa, sem rosto, sem sentimento, interioridade e humanidade.

Bastante significativa para arrematarmos as reflexões apresentadas ao longo desse artigo, tal passagem evidencia a delicada situação vivida, ainda hoje, pela grande maioria dos escritores negros no Brasil. Entretanto, como foi possível observar, livros individuais, antologias de poemas, contos e ensaios, além das demais obras de referência publicadas nos últimos anos, vêm se somando na atual conjuntura para revelar um país "que se quer negro também no campo da produção literária" (CUTI, 2010, p.13). Ao organizar a fala por meio do coletivo, ou seja, através da ação política, uma das principais características que marcam essa vertente específica de nossa literatura é a promoção de transformações culturais profundas. Do mesmo modo, ao se autodeclararem enquanto escritores negros e que desenvolvem uma literatura negra, tais autores contribuem para a consagração do termo, fazendo com que uma gama 
significativa de trabalhos acadêmicos, bem como a realização de encontros, conferências e simpósios temáticos, em âmbito nacional e internacional, surja e se estabeleça a cada dia. $\mathrm{O}$ campo de estudos que trata das relações entre literatura e afrodescendência no Brasil, portanto, já é uma realidade. E, quando houver um lastro ainda maior de pesquisas que contribuam para dar maior visibilidade a esses estudos, não será mais necessário discutir, como fizemos neste artigo, as condições e as possibilidades de sua emergência.

\section{REFERÊNCIAS}

ALVES, Miriam (2012). Cadernos Negros (1): "Estado de alerta no fogo cruzado". In: FIGUEIREDO, Maria do Carmo Lanna; FONSECA, Maria Nazareth Soares (Orgs.). Poéticas afro-brasileiras. 2.ed. Belo Horizonte: Mazza Edições/Editora PUCMinas, p.221-240.

BASTIDE, Roger (1943). A poesia afro-brasileira. São Paulo: Martins Fontes. BERND, Zilá (1987). Negritude e literatura na América Latina. Porto Alegre: Mercado Aberto.

(1988). Introdução à literatura negra. Porto Alegre: Mercado Aberto.

(1992) (Org.). Poesia negra brasileira. Porto Alegre: AGE/IEL/IGEL. BOURDIEU, Pierre (1989). O poder simbólico. Rio de Janeiro: Bertrand Brasil.

BROOKSHAW, David (1983). Raça e cor na literatura brasileira. Porto Alegre: Mercado Aberto.

CAMARGO, Oswaldo de (1987). O negro escrito. Apontamentos sobre a presença do negro na literatura brasileira. São Paulo: Secretaria de Estado da Cultura. 
CEVASCO, Maria Elisa (2003). Dez lições sobre Estudos Culturais. São Paulo: Boitempo Editorial.

CUTI (Luiz Silva) (2010). Literatura negro-brasileira. São Paulo: Selo Negro. DAMASCENO, Benedita Gouveia (1988). Poesia negra no modernismo brasileiro. Campinas: Pontes Editores.

DUARTE, Eduardo de Assis (2011). Entre Orfeu e Exu, a afrodescendência toma a palavra. In: (Org.). Literatura e afrodescendência no Brasil: antologia crítica vol (1). Belo Horizonte: Editora UFMG, p.13-48. (2014). Literatura afro-brasileira. In: SILVA, Cidinha da (Org.). Africanidades e relações raciais: insumos para políticas públicas na área do livro, leitura, literatura e bibliotecas no Brasil. Brasília: Fundação Cultural Palmares, p.41.

FONSECA, Maria Nazareth Soares (2006). Literatura negra, literatura afro-brasileira: como responder à polêmica? In: SOUZA, Forentina; LIMA, Maria Nazaré (Orgs.). Literatura afro-brasileira. Salvador: Centro de Estudos Afro-Orientais/Brasília: Fundação Cultural Palmares, p.9-38.

LOBO, Luiza (1993). Crítica sem juízo. Rio de Janeiro: Francisco Alves.

OLIVEIRA, Dennis de (2016). Dilemas da luta contra o racismo no Brasil. In: Margem esquerda. Revista da Boitempo, n.27. Dossiê: Marxismo e questão racial. São Paulo, p.31-37.

PEREIRA, Amauri Mendes (2008). Trajetória e perspectivas do Movimento Negro Brasileiro. Belo Horizonte: Nandyala.

PROENÇA FILHO, Domício (1988). O negro e a literatura brasileira. In: Boletim Bibliográfico da Biblioteca Mário de Andrade Jan/Dez. São Paulo, 49, p.1-4.

QUEIROZ JÚNIOR, Teófilo de (1975). O preconceito de cor e a mulata na literatura brasileira. São Paulo: Ática.

RABASSA, Gregory (1965). O negro na ficção brasileira. Rio de Janeiro: Tempo Brasileiro.

SAYERS, Raymond (1958). O negro na literatura brasileira. Rio de Janeiro: O Cruzeiro. 
(1983). Onze estudos de literatura brasileira. Rio de Janeiro: Civilização Brasileira; Brasília: Instituto Nacional do Livro. SOVIK, Liv (2009). Aqui ninguém é branco. Rio de Janeiro: Aeroplano Editora.

Rafael Balseiro Zin é Sociólogo (Mtb 2204/SP), com especialização em Estudos Brasileiros: sociedade, educação e cultura. Possui graduação em Sociologia e Política (2012), pela Escola de Sociologia e Política de São Paulo; Mestrado em Ciências Sociais (2016), pela Pontifícia Universidade Católica de São Paulo; e, atualmente, é Doutorando em Ciências Sociais, pela Pontifícia Universidade Católica de São Paulo, onde participa, como pesquisador, do Núcleo de Estudos em Arte, Mídia e Política (Neamp). Contato: rafaelbzin@hotmail.com.

\section{ANEXOS}

Teses e dissertações sobre Maria Firmina dos Reis mencionadas neste artigo:

ABREU, José António Carvalho Dias de (2013). Os abolicionismos na prosa brasileira: de Maria Firmina dos Reis a Machado de Assis. 2013. 472 f. Tese (Doutorado em Letras) - Faculdade de Letras. Universidade de Coimbra, Coimbra.

CARVALHO, Virgínia Silva de (2013). A efígie escrava: a construção de identidades negras no romance Úrsula, de Maria Firmina Dos Reis. 2013. 136 f. Dissertação (Mestrado em Letras) - Centro de Ciências Humanas e Letras. Universidade Estadual do Piauí, Teresina.

CORREIA, Janaína dos Santos (2013). O uso de fontes em sala de aula: a obra de Maria Firmina dos Reis (1859) como mediadora no estudo da escravidão negra no Brasil. 2013. 166 f. Dissertação (Mestrado em História Social) - Centro de Letras e Ciências Humanas. Universidade Estadual de Londrina, Londrina.

DIOGO, Luciana Martins (2016). Da sujeição à subjetivação: a literatura como espaço de construção da subjetividade, os casos das obras "Úrsula" e 
"A Escrava" de Maria Firmina dos Reis. 2016. 220 f. Dissertação (Mestrado em Estudos Brasileiros) - Instituto de Estudos Brasileiros. Universidade de São Paulo, São Paulo.

MENDES, Algemira de Macêdo (2006). Maria Firmina dos Reis e Amélia Beviláqua na história da literatura brasileira: representação, imagens e memórias nos séculos XIX e XX. 2006. 372 f. Tese (Doutorado em Letras) - Faculdade de Letras. Pontifícia Universidade Católica do Rio Grande do Sul, Porto Alegre.

MENDES, Melissa Rocha Teixeira (2013). Uma análise das representações sobre as mulheres no Maranhão da primeira metade do século XIX a partir do romance Úrsula, de Maria Firmina dos Reis. 2013. 149 f. Dissertação (Mestrado em História Social) - Centro de Ciências Humanas. Universidade Federal do Maranhão, São Luís.

NASCIMENTO, Juliano Carrupt do (2009). O romance Úrsula de Maria Firmina dos Reis: estética e ideologia no romantismo brasileiro. 2009. 102 f. Dissertação (Mestrado em Letras Vernáculas) - Faculdade de Letras. Universidade Federal do Rio de Janeiro, Rio de Janeiro.

OLIVEIRA, Adriana Barbosa de (2007). Gênero e etnicidade no romance Úrsula, de Maria Firmina dos Reis. 2007. 107 f. Dissertação (Mestrado em Letras) - Faculdade de Letras. Universidade Federal de Minas Gerais, Belo Horizonte.

PINHEIRO, Thayara Rodrigues (2016). Vozes femininas em Úrsula, de Maria Firmina dos Reis, "uma maranhense". 2016. 94 f. Dissertação (Mestrado em Letras) - Centro de Ciências Humanas, Letras e Artes. Universidade Federal da Paraíba, João Pessoa.

RIO, Ana Carla Carneiro (2015). Autoria, devir e interdição: os "entrelugares" do sujeito no romance Úrsula. 2015. 137 f. Dissertação (Mestrado em Estudos da Linguagem) - Faculdade de Letras. Universidade Federal de Goiás, Catalão.

SANTOS, Katiana Souza (2015). Relações de gênero na segunda metade do século XIX na perspectiva de Maria Firmina dos Reis: análise do romance Úrsula. 2015. 135 f. Dissertação (Mestrado em Cultura e Sociedade) - 
Centro de Ciências Humanas. Universidade Federal do Maranhão, São Luís.

SANTOS, Carla Sampaio dos (2016). A escritora Maria Firmina dos Reis: história e memória de uma professora no Maranhão do século XIX. 2016. 126 f. Dissertação (Mestrado em Educação) - faculdade de Educação. Universidade Estadual de Campinas, Campinas.

SILVA, Régia Agostinho da (2013). A escravidão no Maranhão: Maria Firmina dos Reis e as representações sobre escravidão e mulheres no Maranhão na segunda metade do século XIX. 2013. 177 f. Tese (Doutorado em História Econômica) - Faculdade de Filosofia, Letras e Ciências Humanas. Universidade de São Paulo, São Paulo.

TELLES, Norma (1987). Encantações: escritoras e tradição literária no Brasil, século XIX. 1987. 531 f. Tese (Doutorado em Ciências Sociais) Faculdade de Ciências Sociais. Pontifícia Universidade Católica de São Paulo, São Paulo.

ZIN, Rafael Balseiro (2016). Maria Firmina dos Reis: a trajetória intelectual de uma escritora afrodescendente no Brasil oitocentista. 2016. $100 \mathrm{f}$. Dissertação (Mestrado em Ciências Sociais) - Faculdade de Ciências Sociais. Pontifícia Universidade Católica de São Paulo, São Paulo. 